Int. J. Dev. Biol. 54: 1723-1728 (2010)

doi: $10.1387 / \mathrm{ijdb} .103204 \mathrm{hs}$

\title{
Comparison of reprogramming ability of mouse ES and iPS cells measured by somatic cell fusion
}

\author{
HUSEYIN SUMER ${ }^{1}$, CRAIG NICHOLLS ${ }^{2}$, JUN LIU1ํ, POLLYANNA A. TAT ${ }^{1}$, \\ JUN-PING LIU² and PAUL J. VERMA*,1 \\ ${ }^{1}$ Centre for Reproduction and Development, Monash Institute of Medical Research, Monash University and \\ ${ }^{2}$ Department of Immunology, Central Clinical School, AMREP, Monash University, Melbourne, Australia
}

\begin{abstract}
The ectopic expression of the key transcription factors Oct4, Sox2, c-Myc, and KIf-4 have been shown to reprogram somatic cells to a pluripotent state. In turn these induced pluripotent stem (iPS) cells, like embryonic stem (ES) cells, have been shown to be able to reprogram somatic cells by cell fusion. In this study we compare the differences and similarities between ES and iPS cells measured by somatic cell fusion to somatic cells harboring an Oct4-GFP transgene. We found that iPS cells were just as potent as ES cells at reprogramming the somatic genome as measured by Oct4-GFP reactivation. The resulting ES-somatic and iPS-somatic cell hybrids were characterized for expression of key pluripotency genes, immunostaining for Oct4, SSEA-1, and the ability to differentiate into cell types representative of the three germ layers. In addition to restoring pluripotency to the somatic genome following cell fusion, the telomere maintenance mechanisms of both the ES and iPS cells were found to be dominant in the resulting ES-somatic and iPS-somatic cell hybrids, resulting in the lengthening of the somatic telomeres following cellular reprogramming. Therefore this study supports the view that iPS cells can be virtually indistinguishable from ES cells, even with regard to their reprogramming ability.
\end{abstract}

KEY WORDS: cell fusion, reprogramming, induced pluripotent stem cell, ES cell

\section{Introduction}

Somatic cells can be reprogrammed to a pluripotent state by a number of methods including; somatic cell nuclear transfer (SCNT), cell fusion to ES cells, and induction of pluripotency by defined factors. The mechanisms, efficiency and timing of reprogramming of the different methods vary substantially and their study has aided in the delineation of the reprogramming process.

SCNT involves the transfer of a differentiated nucleus to an enucleated oocyte and can completely reprogram differentiated mammalian nuclei to a totipotent state able to produce live offspring (Wilmut et al., 1997). Autologous ES cells can be isolated from SCNT embryos, termed ntES cells, which possess all the properties of pluripotent stem cells including the ability to differentiate into functional cell types for autologous therapeutic cell transplantation(Rideout et al., 2002). Furthermore, SCNT based reprogramming has been shown to restore the epigenetic profile of somatic cells to a pluripotent state, including telomere length. Telomeres are the protein-DNA structures at the ends of chromosomes which protect chromosome ends from digestion by exonucleases, prevent aberrant recombination, facilitate attachment of chromosome ends to the nuclear envelope and enable complete replication of DNA (Blackburn, 1991). Telomere length and stability is most commonly maintained by telomerase, a ribonucleoprotein reverse transcriptase complex that synthesises telomeric DNA and is highly expressed in germ cells, stem cells, tumor cells, and most immortal cell lines. In the absence of telomerase, as is the case in somatic cells, telomeres progressively shorten with each cell division eventually reaching a critical point at which cells are susceptible to chromosomal aberrations and aneuploidy, and can trigger cell senescence and apoptosis (Blackburn, 1991). Studies in mice (Tian et al., 2000; Wakayama et al., 2000), pigs (Jiang et al., 2004), and cattle (Betts et al., 2001) show that telomere lengths in clones were equivalent to age matched control animals suggesting that telomeres can be reprogrammed through the cloning process.

Abbreviations used in this paper: ES, embryonic stem cell; iPS, induced pluripotent stem cell; MEF, mouse embryonic fibroblast (cell).

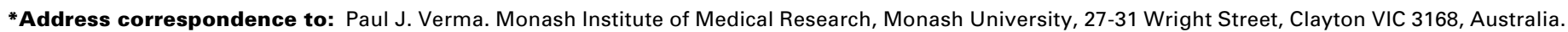
Fax: +61-3-9594-7416. e-mail: Paul.Verma@monash.edu 
Reprogramming by cell fusion involves the hybridization of somatic cells with ES cells resulting in an ES-somatic cell hybrid. ES cells from both mouse (Tada et al., 2001) and human (Cowan et al., 2005; Yu et al., 2006), have been shown to reprogram somatic cells by cell fusion. The resulting ES-somatic cell hybrids have most properties of pluripotency in vitro, such as gene expression profiles and epigenetic regulation, and are able to differentiate into cell types of the three germ lineages in teratoma assays when injected into immuno-compromised mice (Cowan et al., 2005; Tada et al., 2001; Yu et al., 2006). Furthermore, telomerase activity in ES-somatic hybrids is observed to be high and similar to those of ES cells (Hanna et al., 2007), resulting in the lengthening of the somatic cell derived chromosomes telomeres (Sumer etal., 2010b).

More recently, the induced expression of the transcription factors; Oct4, Sox2, c-Myc, and KIf-4 in both mouse (Takahashi and Yamanaka, 2006) and human (Takahashi et al., 2007) somatic cells has been shown to reprogram the cells to a pluripotent state termed 'induced pluripotent stem' cells. The functional properties of iPS cells have been demonstrated by their ability to contribute to the germ-line of chimeras (Okita et al., 2007) and generation of offspring following aggregation with tetraploid embryos (Boland et al., 2009; Zhao et al., 2009) as well as their use in differentiation and transplantation studies in disease models in rodents (Hanna et al., 2007). Furthermore, increased telomerase activity has also been shown in both mouse (Stadtfeld et al., 2008; Takahashi et al., 2007; Takahashi and Yamanaka, 2006) and human (Yu et al., 2006) iPS

cells, resulting in the lengthening of telomeres (Marion et al., 2009).

It has been previously reported that both iPS (Maherali et al., 2007; Sumer et al., 2010a) and ntES cells (Sumer et al., 2010a) can reprogram somatic cells by cell fusion. These results suggest that once a somatic cell nucleus is reprogrammed, it itself has the capacity and potency to reprogram other somatic cells by cell fusion - a functional property shared with ES cells. In the present study we compare the efficiency of cell fusion based reprogramming of both ES and iPS cells fused to somatic cells harboring an Oct4-GFP transgene. Further, we characterize the pluripotency properties of the resulting cell hybrids and compared the gene expression profiles as well as the extent of telomeric reprogramming by analysis of telomerase activity as well as telomere length.

\section{Results}

\section{Reprogramming of somatic cells after fusion with ES and iPS cells}

To evaluate the cell fusion based reprogramming efficiency of both ES and iPS cells we performed polyethylene glycol (PEG) mediated cell fusion with these pluripotent stem cells to MEFs isolated from OG2 transgenic mice, which contain a GFP reporter under the control of the Oct4 promoter region (Fig. 1A). Oct4-GFP reactivation from the somatic cell was observed within 72 hours of cell fusion for both ES and iPS cells. Seven days post fusion, $87 \pm$ $21(n=3)$ GFP +ve colonies were observed following ES-somatic cell fusion, while $175 \pm 48(n=3)$ GFP + ve colonies were ob-

B

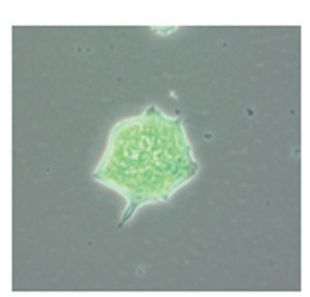

OG2 MEF (Oct4-GFP)

Cell Fusion and Oct4-GFP activation
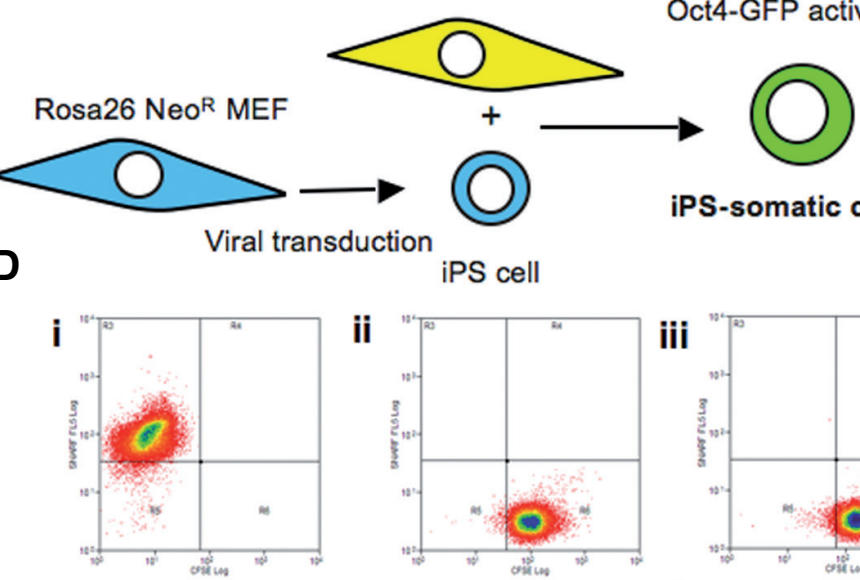

iPS-somatic cell hybrid iPs iPS cell ii
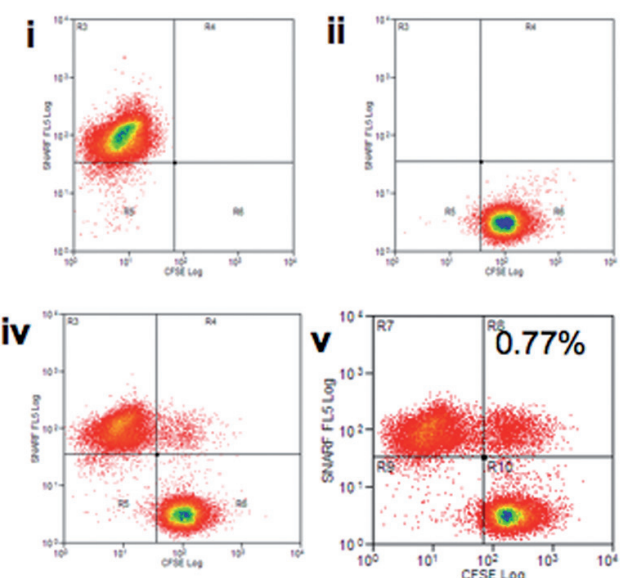

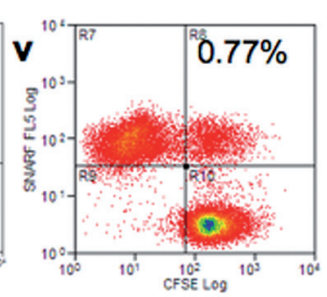

iii

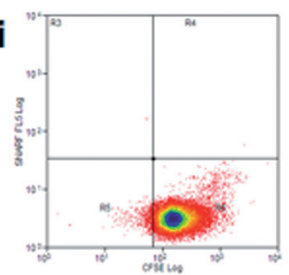

vi

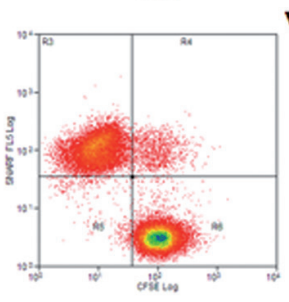

vii

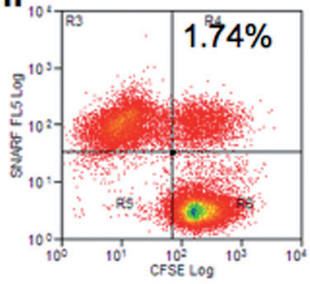
served following iPS-somatic cell fusion (Fig. 1 B,C). In order to determine the reprogramming rate, the fusion efficiency was determined in parallel experiments in which the pluripotent cells were stained with CFSE and the MEFs stained with SNARF-1 prior to fusion. The somatic cell fusion efficiencies were determined to be $0.77 \% \quad 0.21$ and $1.74 \% \quad 0.44$ $(n=3)$, for the ES and iPS cells,

Fig. 1. Generation of cell hybrids. (A) ES-somatic and iPS-somatic cell hybrids were generated by cell fusion between ES D3 cells or iPS cells with OG2 MEFs harbouring an Oct4-GFP transgene. Morphology and Oct4-GFP reactivation of (B) ES-somatic and (C) iPS-somatic cell hybrids. (D) FACs profiles to determine fusion efficiency, (i) SNARF-1 stained OG2 MEFs, CFSE stained (ii) ES and (iii) iPS cells, (iv) co-culture of OG2 MEFs and ES cells, (v) cell fusion of OG2 MEFs and ES cells, (vi) co-culture of OG2 MEFs and iPS cells, (v) cell fusion of OG2 MEFs and iPS cells. 
respectively (Fig. 1D). The cell fusion based reprogramming rate for the ES and iPS cells were determined to be $0.0114 \%$ and $0.0100 \%$ respectively and were not found to be significantly different $(p=0.596)$.

\section{Characterization of cell hybrids}

Individual GFP + ve ES-somatic and iPS-somatic cell hybrid colonies were picked and expanded by enzymatic passaging and two clones of each were used for further analysis, designated ESMEF 1 and 2, and iPS-MEF 1 and 2. The hybrids were shown to have double the DNA content of the two parental cell lines by flow cytometry analysis (Fig. 2A). Furthermore, the cell cycle profiles of the two hybrid lines were shown to be similar to that of ES and iPS cells with the majority of cells were in $S$ and G2/M phase, while the majority of the MEF cells were in $\mathrm{GO} / 1$ phase.

The hybrids were further characterized for their pluripotent properties in vitro and in vivo. Both the ES-somatic and iPS-somatic hybrids were shown to express the pluripotency markers Oct-4, Sox2, Nanog, and Rex1, while the fibroblast specific marker $S P A R C$ was shown to be silenced in the hybrids (Fig. 2B). Both ES-somatic (data not shown) and iPS-somatic cell hybrids were also shown to have high levels of alkaline phosphatase activity (Fig. 2C), and showed the expected protein localisation for the pluripotency markers SSEA-1 to the cell surface (Fig. 2D) and Oct4 to the nucleus (Fig. 2E). Both ESsomatic (data not shown) and iPS-somatic cell hybrids were able to form embryoid bodies in the absence of LIF (Fig. 2F), and the pluripotency of the hybrids were confirmed by teratoma assay by injecting the cells into the thigh muscle of SCID mice. All mice from both ES-somatic (data not shown) and iPSsomatic cell hybrid injections developed teratomas, which contained tissues representative of the three germ layers; endoderm, ectoderm and mesoderm (Fig. 2G).

\section{Telomeric reprogramming in ES-somatic and iPS-somatic cell hybrids}

Telomeric reprogramming has been observed following cell reprogramming by SCNT, cell fusion and iPS cell induction. We next evaluated the extent of telomeric reprogramming following both ES-somatic and iPS-somatic cell fusion. Firstly, quantitative FISH was performed using a telomere-specific fluorescent probe on metaphase spreads of the various cell hybrids, alongside the MEF, ES and iPS parental cell lines (Fig. 3A). In order to compare the relative length of telomeres across the various cell lines, quantification of telomere fluorescence intensities of metaphase spreads was conducted using TFL-telo 2.2 software. Consistent with previ- ous data (Sumer et al., 2010b), increased telomere fluorescence intensity was observed in ES cells compared to MEFs, with ES cell telomeres an average of 2.3 times longer than the MEF cell line telomeres. Similarly the induction of pluripotency of the QS MEFs resulted in iPS cells with a mean telomere fluorescence 2.5 fold longer following reprogramming (Fig. 3 A,B). Examination of telomere fluorescence intensity frequencies of the ES-somatic hybrids showed a skewing of telomere length to that resembling the ES cell lines, suggesting that the somatic telomeres had been lengthened following cell fusion. Furthermore, following iPS-somatic cell fusion the mean telomere length of the resulting hybrids were also found to be of a similar length to the pluripotent iPS cell parental line.

Previous studies have shown that telomerase activity in ES-

\section{A i}

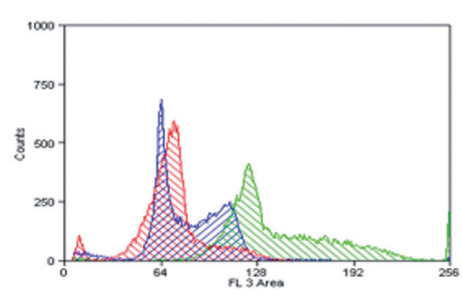

B

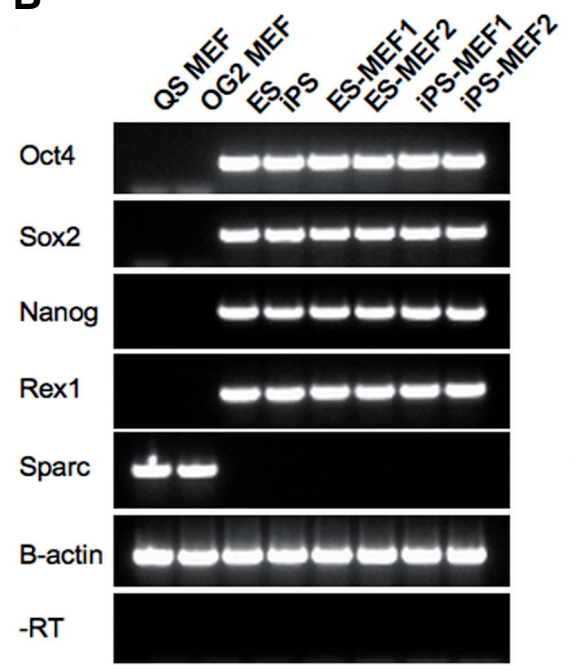

$\mathbf{F}$

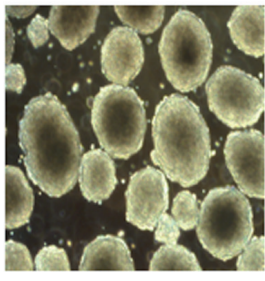

\section{$\mathbf{B}$}

ii

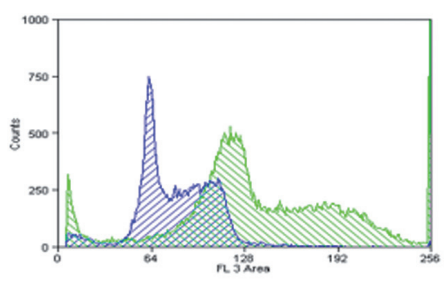

D

E

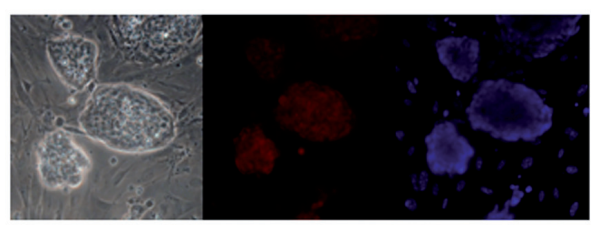

\section{.}
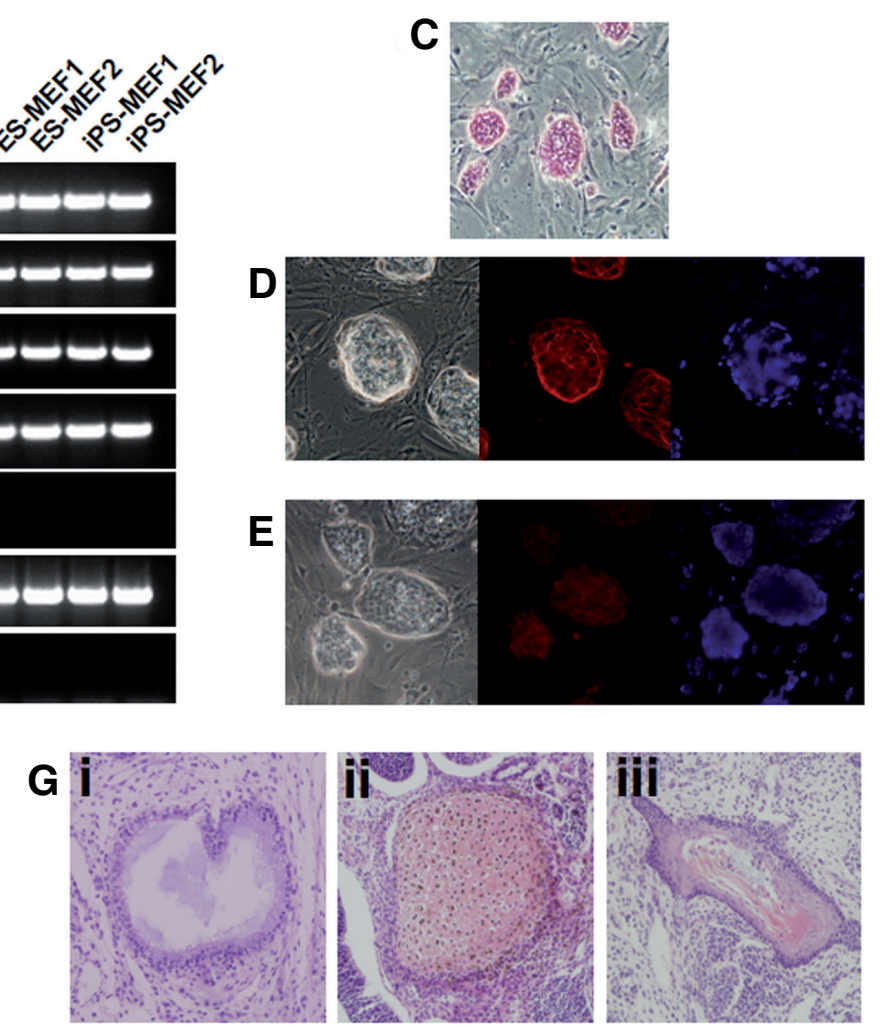

Fig. 2. Characterisation of cell hybrids. (A) Cell cycle DNA profiles. (i) ES shown in blue, MEF in red and ES-somatic cell hybrid in green, (ii) iPS shown in blue and iPS-somatic cell hybrid in green. (B) Gene expression profile of the cell hybrids and the two parental cell lines. (C) Alkaline phosphotase activity of an iPS-somatic cell hybrid. (D) SSEA-1 immunostaining of an iPS-somatic hybrids showing phase, counter stained with DAPI in blue. (E) Oct4 immunostaining of an iPSsomatic hybrids showing phase, Oct4 staining in red, counter stained with DAPI in blue. (F) Embryoid body formation of iPS-somatic cell hybrids in the absence of LIF, scale bar $500 \mu M$. (G) Histology of teratoma tissue derived from an iPS-somatic cell hybrid showing (i) Secretory epithelium, (ii) cartilage and (iii) dermal tissue. Scale bars, $200 \mu \mathrm{M}$. 
A

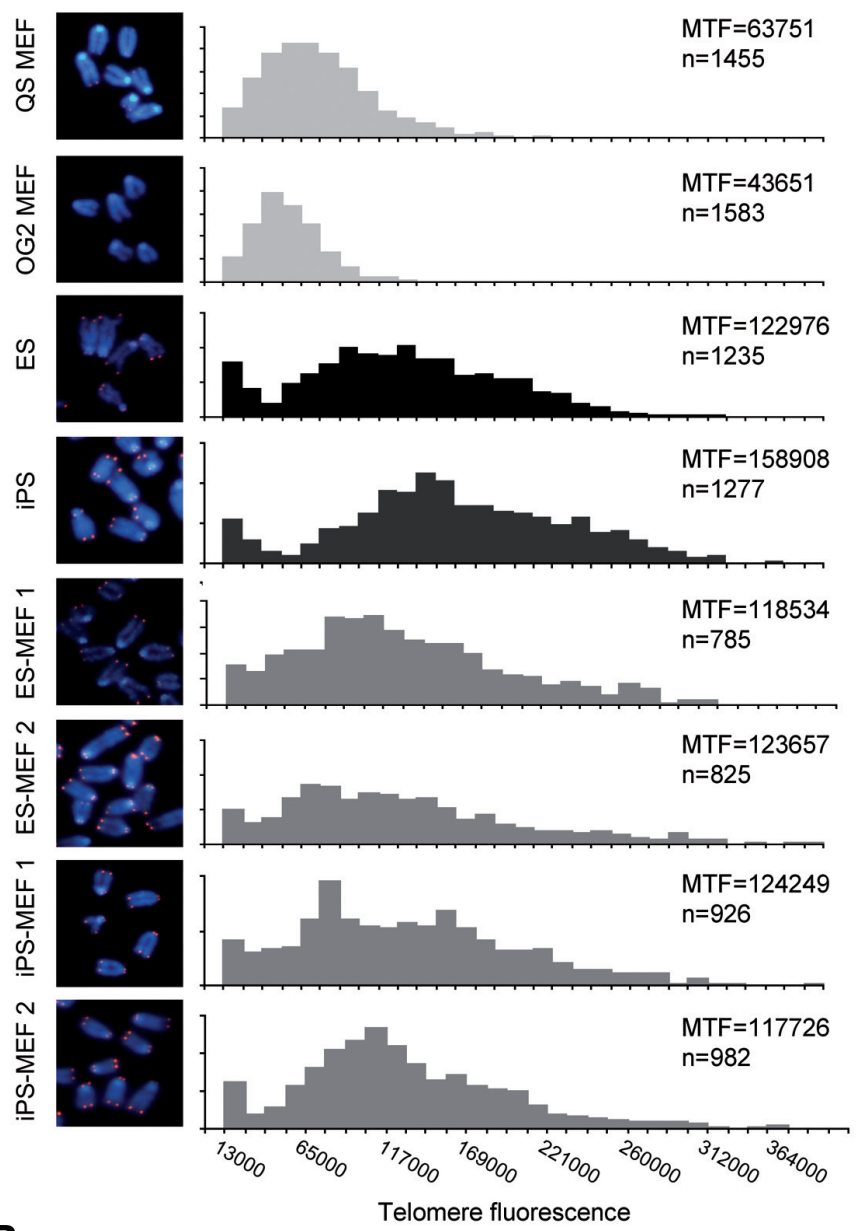

B

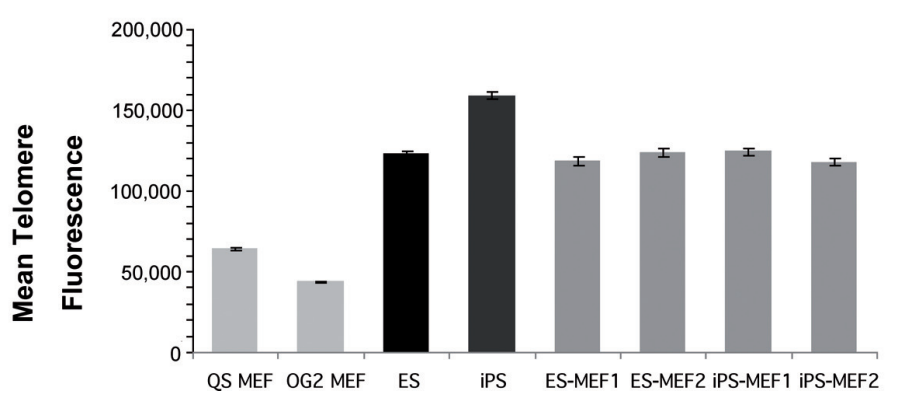

A

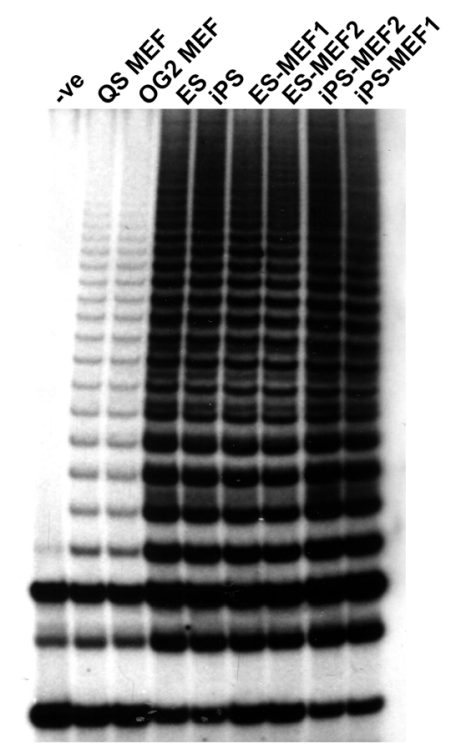

B

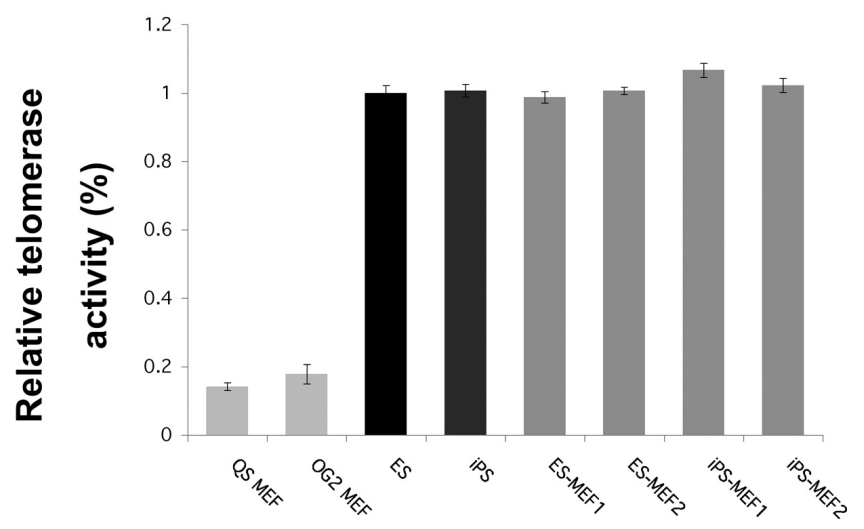

Fig. 3 (Left). Telomere lengthening following cell fusion. (A) Representative Q-FISH signal (arbitrary units) using a telomere probe on metaphase chromosomes. Graphical representation of Q-FISH telomere length analysis showing a higher mean telomere fluorescence (MTF) in ES and iPS cells compared to MEFs, while both ES-somatic and iPSsomatic cell hybrids have a high MTF similar to those of the pluripotent parental cell lines. (B) Mean telomere fluorescence of Q-FISH signals showing higher telomere fluorescence signal in the ES, iPS and somatic cell hybrid cell lines and lower fluorescence in MEFS.

Fig. 4 (Right). Telomerase activity following cell fusion. (A) Telomerase activity as determined by TRAP assay for the various cell lines including a negative control. (B) Densitometric analysis of TRAP autoradiographs showing equivalently high levels of telomerase activity in cell lysates of the ES, iPS and somatic cell hybrid cell lines and lower activity in MEFs.

somatic cell hybrids is high and similar to those of ES cells (Cowan et al., 2005; Sumer et al., 2010b), and may be the underlying mechanism for the lengthening of the somatic cell derived chromosomes telomeres in hybrids (Sumer et al., 2010b). Telomere repeat amplification protocol (TRAP) assay was conducted on cell lysates from equal number of cells in order to determine the levels of telomerase activity of the various cell lines (Fig. 4A). Both ES and iPS cells were shown to have significantly higher telomerase activity $(p<0.05, n=3)$ when compared to the MEF cell lines (Fig. $4 \mathrm{~B})$. Furthermore, both the ES-somatic and iPS-somatic cell hybrids had equally higher levels of telomerase activity, suggesting that the mechanisms regulating telomerase activity of the pluripotent cell line is dominant in the resulting cell hybrids.

\section{Discussion}

One of the functional properties of pluripotent cells is that they have the capacity to reprogram somatic cells by cell fusion. It has previously been shown that both mouse iPS (Maherali et al., 2007; Sumer et al., 2010a) and SCNT derived ntES cells 
(Sumer et al., 2010a), like ES cells, have the ability to reprogram a somatic genome following cell fusion. In the present study we have shown that iPS cells are as efficient as ES cells at reprogramming somatic cells by cell fusion. In addition to restoring pluripotency to the somatic genome following cell fusion, the telomere maintenance mechanisms of both the ES and iPS cells are dominant in the ES-somatic as well as iPSsomatic cell hybrids resulting in the lengthening of the somatic telomeres following cellular reprogramming.

iPS cells were shown to have a higher somatic cell fusion efficiency when compared to ES cells (Fig. 1). Despite this the reprogramming rate was determined to be similar between the two cell lines, suggesting that iPS cells are just as efficient as ES cells at reprogramming somatic cells by cell fusion. Furthermore, the re-activation of the somatic cell derived Oct4 driven transgene was observed to occur at a similar time post-fusion. The resulting cell hybrids have a number of ES cell characteristics including: cell-cycle profile, gene expression of the stem cell markers Oct4, Sox2, Nanog and Rex-1, and the silencing of the differentiation marker SPARC. The hybrids also stained positively for the stem cell markers AP, SSEA1 and Oct4 and gave rise to teratomas comprised of tissues from the three germ layers when injected into immune compromised mice.

Telomere regulation and maintenance is critical for pluripotent stem cells. ES cells have relatively high telomerase activity and long telomeres, in contrast to differentiated somatic cells which possess relatively low telomerase activity and short telomeres. This is due to the repression of telomerase during differentiation which coincides with telomere shortening, which can ultimately lead to replicative senescence (Osterhage and Friedman, 2009). It has previously been shown that telomerase activity and telomere lengthening occurs following reprogramming by SCNT (Tian et al., 2000; Wakayama et al., 2000), the induction of pluripotency by transcription factors (Marion et al., 2009; Takahashi and Yamanaka, 2006) and ES-somatic cell fusion (Cowan et al., 2005; Sumer et al., 2010b). In the present study we report that the length of telomeres and levels of telomerase activity appeared to be restored to pluripotent stem cell levels in both ES-somatic and iPS-somatic cell hybrids. The mechanism of telomerase activation in fusion cells requires further investigation in the future. We cannot exclude the possibility that epigenetic mechanisms may differentially influence the telomerase catalytic subunit gene promoter on chromosomes deriving from the initial pluripotent cells versus those from somatic cells. However, these results demonstrate that the telomerase maintenance of telomeres in both parental pluripotent ES and iPS cells plays a dominant role in the hybrids. It is possible that that the induction of pluripotency by the transcription factors Oct4, Sox2, c-Myc and KIf4 in a somatic cell results in an iPS cell that not only has the capacity to restore pluripotency to other somatic cells by cell fusion, but can also enforce a new telomere maintenance program that results in longer somatic telomeres.

In summary, iPS cells are just as efficient ES cells at reprogramming somatic cells by cell fusion. We confirm that iPS cells are equally dominant over a somatic cell following cell fusion and can enforce both pluripotency and other cellular processes such as the telomere length regulation and maintenance in the resulting cell hybrids.

\section{Materials and Methods}

\section{Cell culture and differentiation}

Feeder-independent mouse ESD3, iPS cells, ES-somatic and iPSsomatic cell hybrids were cultured in ES media: DMEM (Invitrogen) supplemented with $15 \%$ Hyclone fetal bovine serum, $1 \mathrm{mM} \mathrm{L}$-glutamine (Invitrogen), $0.1 \mathrm{mM} \beta$-mercaptoethanol (Sigma), $1000 \mathrm{U} / \mathrm{mL}$ LIF (Chemicon), 1\% non-essential amino acids (Invitrogen) and 0.5\% Penicillin-Sreptomycin (Invitrogen). Mouse embryonic fibroblasts were cultured in the same medium without LIF and b-mercaptoethanol. Cultures were maintained in a humidified incubator at $37^{\circ} \mathrm{C}$, with $5 \% \mathrm{CO}_{2} / 95 \%$ air. To examine teratoma formation, $1-2 \times 10^{6}$ cells were injected into the rear leg muscle of 4-6 week old severe combined immunodeficient (SCID) mice. After 4 weeks, the teratomas were excised and fixed in $4 \%$ paraformaldehyde, embedded in paraffin, sectioned at $5 \mu \mathrm{M}$ and stained with hematoxylin and eosin by the MIMR Histology Laboratory core facility.

\section{Cell fusion}

PEG mediated cell fusion was performed in a 4 well Nunc tissue culture plate as previously described (Sumer et al., 2009). In brief, ES or iPS cells were plated at $0.5 \times 10^{6}$ cells per cellular fibronectin (Sigma) coated well and cultured overnight. $1 \times 10^{6} \mathrm{OG} 2 \mathrm{MEFs}$ isolated from OG2 transgenic mice (Tat et al., 2010), which contain a GFP reporter under the control of the Oct4 promoter region, were centrifuged onto the dense monolayer at $400 \mathrm{~g}$ for $10 \mathrm{mins}$. The culture medium was removed and fusion performed by adding $500 \mu \mathrm{L}$ of $50 \% \mathrm{PEG}_{1500} / 150 \mathrm{mM} \mathrm{HEPES}$ and incubated at room temperature for 2 mins. The PEG was removed, the cells washed 4 times in calcium-and-magnesium-free PBS and allowed to recover in ES medium in the incubator for at least $4 \mathrm{~h}$ before the contents of the plate were trypsinised and plated onto $10 \mathrm{~cm}$ dishes for further culture. ESsomatic and iPS-somatic cell hybrids were identified by Oct4-GFP reactivation and clones were picked and expanded for further analysis.

Fusion efficiency was determined by pre-staining the different cells with cellular dyes prior to fusion. ES and iPS cells were stained with 1.25 $\mu \mathrm{M}$ CFSE (green) for 10 minutes 24 hours prior to fusion, and MEF cells were stained with the $15 \mu \mathrm{M}$ SNARF-1 (red), for 30 minutes an hour prior to fusion. The percentages of double positive stained cells were measured by flow cytometry 3-4 hours post fusion. The fusion efficiency was calculated by subtracting the double positive value in mock fusions from the fusion value. To estimate the reprogramming rate the number of GFP colonies observed was divided by the number of fused MEFs obtained from fusion. Where, the number of fused MEFs is estimated to be the average fusion rate percentage multiplied by $1 \times 10^{6} \mathrm{MEF}$ (the starting number of MEF).

\section{$R T-P C R$}

Total RNA was extracted from cells using the RNeasy kit (Qiagen) according to the manufacturer's instructions. To remove contaminating genomic DNA the resulting total RNA was subjected to DNasel treatment using the DNA-free kit (Ambion). $2 \mu \mathrm{g}$ of RNA was used to synthesize cDNA using the SuperScript III reverse transcriptase kit (Invitrogen). cDNA samples were subjected to PCR amplification with the following primer pairs:

\section{Oct4 F, GTTCAGCCAGACCACCATCT}

$$
\text { R, CCTGGGAAAGGTGTCCTGTAG }
$$

Rex1 F, GGACTAAGAGCTGGGACACG

R, GCTGCTTCCTTCTTGAACAAT

Nanog F, TCAAGGACAGGTTTCAGAAGCA

R, GCTGGGATACTCCACTGGTG

Sox2 F, GAGGAGAGCGCCTGTTTTT

R, GGAGATCTGGCGGAGAATAG

SPARC F, AATTTGAGGACGGTGCAGAGG R, GGTTGTTGCCCTCATCTCTCT 


\section{$\beta$-actin $\mathrm{F}$, GGAATCCTGTGGCATCCATGAAAC}

\section{R, AAAACGCAGCTCAGTAACAGTCCG}

\section{Histochemistry and Immnuohistochemistry}

Cells were cultured in 4 well glass culture slides (BD Falcon) and fixed in $4 \%$ paraformaldehyde for 10 minutes, washed 3 times with PBS and incubated with blocking solution (5\% goat serum, $1 \%$ BSA in PBS) or blocking solution with $0.1 \%$ Triton-X for SSEA-1 and Oct4 primary antibodies respectively before being exposed to the primary antibodies at 1:100 dilution overnight at $4^{\circ} \mathrm{C}$. Following three washes with PBS the slides were incubated at room temperature for one hour with secondary antibodies goat $\alpha$-mouse IgM Alexa 594 or goat $\alpha$-mouse IgG Alexa 594 (Invitrogen), respectively, diluted 1:1000 in blocking solution. Following 3 washes with PBS and the slides were mounted in Vectashield + DAPI) (Vector Laboratories) with a coverslip. Alkaline phosphatase activity was detected with an AP kit (Chemicon) according to the manufacturer's instructions

\section{Telomerase activity}

Telomerase activity was determined as previously described (Li et al., 1997). Briefly, cells were washed and lysed by detaching and passing the cells though a $26.5 \mathrm{G}$ needle attached to a $1-\mathrm{mL}$ syringe in prechilled TRAP lysis buffer. Protein extracts from equal numbers of cells (250) were incubated with telomeric DNA substrate and deoxynucleotide triphosphates, and newly synthesized telomeric DNAs were observed after PCR using specific telomeric DNA primers and [a-32P]ATP (Perkin Elmer), polyacrylamide slab gel electrophoresis, and autoradiography. As an internal control of the PCR and loading, the primers NT (ATCGCTTCTCGGCCTTTT) and TSNT (AATCCGTCGAGCAGAGTTAA AAGGCCGAGAAGCGAT) were included in the reaction. Telomerase activity was quantified by densitometry.

\section{Quantitative fluorescence in situ hybridization (Q-FISH) telomere length analysis}

For telomere Q-FISH analysis slides with metaphase spreads from cycling cells were generated using standard laboratory protocols. Slides were fixed in $4 \%$ formaldehyde before treatment with Digest-All-3 pepsin solution (Invitrogen) and hybridized with probe solution $(0.3 \mu \mathrm{g} / \mathrm{ml}$ Cy3conjugated [CCCTAA $]_{3}$ PNA probe (Panagene, Daejeon, South Korea), $70 \%$ formamide, $20 \mathrm{mM}$ Tris- $\mathrm{HCl}, \mathrm{pH} 7.0,1 \% \mathrm{BSA}$ ). Washing was conducted in PBS $/ 0.1 \%$ tween-20 with one high stringency wash at $57^{\circ} \mathrm{C}$. DNA was counterstained with DAPI and visualized and captured using Plan Fluor 100x oil-immersion objective. Mean Telomere Fluorescence (MTF - arbitrary units) was determined using the TFL-Telo 2.2 (gift from Dr. Peter Landsorp, Vancouver). Images from at least 10 metaphase spreads from each data point were quantified before assembly of data in a standard spreadsheet program.

\section{Acknowledgements}

This project was supported by funding from the Australian Stem Cell Centre, National Health and Medical Research Council of Australia, and Cancer Council of Victoria, Australia, and by the Victorian Government's Operational Infrastructure Support Program.

\section{References}

BETTS, D., BORDIGNON, V., HILL, J., WINGER, Q., WESTHUSIN, M., SMITH, L. and KING, W. (2001). Reprogramming of telomerase activity and rebuilding of telomere length in cloned cattle. Proc Natl Acad Sci USA 98: 1077-1082.

BLACKBURN, E.H. (1991). Structure and function of telomeres. Nature 350: 569573.

BOLAND, M.J., HAZEN, J.L., NAZOR, K.L., RODRIGUEZ, A.R., GIFFORD, W., MARTIN, G., KUPRIYANOV, S. and BALDWIN, K.K. (2009). Adult mice gener- ated from induced pluripotent stem cells. Nature 461: 91-94.

COWAN, C.A., ATIENZA, J., MELTON, D.A. and EGGAN, K. (2005). Nuclear reprogramming of somatic cells after fusion with human embryonic stem cells. Science 309: 1369-1373.

HANNA, J., WERNIG, M., MARKOULAKI, S., SUN, C.W., MEISSNER, A., CASSADY J.P., BEARD, C., BRAMBRINK, T., WU, L.C., TOWNES, T.M. et al. (2007). Treatment of sickle cell anemia mouse model with iPS cells generated from autologous skin. Science 318: 1920-1923.

JIANG, L., CARTER, D.B., XU, J., YANG, X., PRATHER, R.S. and TIAN, X.C. (2004). Telomere lengths in cloned transgenic pigs. Biol Reprod 70: 1589-1593.

LI, H., ZHAO, L.L., FUNDER, J.W. and LIU, J.P. (1997). Protein phosphatase 2A inhibits nuclear telomerase activity in human breast cancer cells. J Biol Chem 272: 16729-16732.

MAHERALI, N., SRIDHARAN, R., XIE, W., UTIKAL, J., EMINLI, S., ARNOLD, K., STADTFELD, M., YACHECHKO, R., TCHIEU, J., JAENISCH, R. et al. (2007). Directly reprogrammed fibroblasts show global epigenetic remodeling and widespread tissue contribution. Cell Stem Cell 1: 55-70.

MARION, R.M., STRATI, K., LI, H., TEJERA, A., SCHOEFTNER, S., ORTEGA, S. SERRANO, M. and BLASCO, M.A. (2009). Telomeres acquire embryonic stem cell characteristics in induced pluripotent stem cells. Cell Stem Cell 4: 141-154.

OKITA, K., ICHISAKA, T. and YAMANAKA, S. (2007). Generation of germlinecompetent induced pluripotent stem cells. Nature 448: 313-317

OSTERHAGE, J.L. and FRIEDMAN, K.L. (2009). Chromosome end maintenance by telomerase. J Biol Chem 284: 16061-16065.

RIDEOUT, W.M., 3RD, HOCHEDLINGER, K., KYBA, M., DALEY, G.Q. and JAENISCH, R. (2002). Correction of a genetic defect by nuclear transplantation and combined cell and gene therapy. Cell 109: 17-27.

STADTFELD, M., MAHERALI, N., BREAULT, D.T. and HOCHEDLINGER, K. (2008). Defining molecular cornerstones during fibroblast to iPS cell reprogramming in mouse. Cell Stem Cell 2: 230-240.

SUMER, H., JONES, K.L., LIU, J., HEFFERNAN, C., TAT, P.A., UPTON, K.R. and VERMA, P.J. (2010a). Reprogramming of somatic cells after fusion with induced pluripotent stem cells and nuclear transfer embryonic stem cells. Stem Cells Dev 19: 239-246.

SUMER, H., JONES, K.L., LIU, J., ROLLO, B.N., VAN BOXTEL, A.L., PRALONG D. and VERMA, P.J. (2009). Transcriptional changes in somatic cells recovered from embryonic stem-somatic heterokaryons. Stem Cells Dev 18: 1361-1368.

SUMER, H., NICHOLLS, C., PINTO, A.R., INDRAHARAN, D., LIU, J., LIM, M.L. LIU, J.P. and VERMA, P.J. (2010b). Chromosomal and telomeric reprogramming following ES-somatic cell fusion. Chromosoma 119: 167-176.

TADA, M., TAKAHAMA, Y., ABE, K., NAKATSUJI, N. and TADA, T. (2001). Nuclear reprogramming of somatic cells by in vitro hybridization with ES cells. Curr Bio 11: 1553-1558.

TAKAHASHI, K., TANABE, K., OHNUKI, M., NARITA, M., ICHISAKA, T., TOMODA, K. and YAMANAKA, S. (2007). Induction of pluripotent stem cells from adult human fibroblasts by defined factors. Cell 131: 861-872.

TAKAHASHI, K. and YAMANAKA, S. (2006). Induction of pluripotent stem cells from mouse embryonic and adult fibroblast cultures by defined factors. Cell 126: 663-676.

TIAN, X.C., XU, J. and YANG, X. (2000). Normal telomere lengths found in cloned cattle. Nat Genet 26: 272-273

WAKAYAMA, T., SHINKAI, Y., TAMASHIRO, K.L., NIIDA, H., BLANCHARD, D.C. BLANCHARD, R.J., OGURA, A., TANEMURA, K., TACHIBANA, M., PERRY, A.C. et al. (2000). Cloning of mice to six generations. Nature 407: 318-319.

WILMUT, I., SCHNIEKE, A.E., MCWHIR, J., KIND, A.J. and CAMPBELL, K.H. (1997). Viable offspring derived from fetal and adult mammalian cells. Nature 385: 810-813.

YU, J., VODYANIK, M.A., HE, P., SLUKVIN, II and THOMSON, J.A. (2006). Human embryonic stem cells reprogram myeloid precursors following cell-cell fusion. Stem Cells 24: 168-176.

ZHAO, X.Y., LI, W., LV, Z., LIU, L., TONG, M., HAI, T., HAO, J., GUO, C.L., MA Q.W., WANG, L. et al. (2009). iPS cells produce viable mice through tetraploid complementation. Nature 461: 86-90. 


\section{Further Related Reading, published previously in the Int. J. Dev. Biol.}

See our recent Special Issue Placenta edited by Joan S. Hunt and Kent L. Thornburg at: http://www.ijdb.ehu.es/web/contents.php?vol=54\&issue=2-3

Modulation of mitochondrial biogenesis and bioenergetic metabolism upon in vitro and in vivo differentiation of human ES and iPS cells Alessandro Prigione and James Adjaye

Int. J. Dev. Biol. (doi: 10.1387/ijdb.103198ap)

Enhancing somatic nuclear reprogramming by Oct4 gain-of-function in cloned mouse embryos

Martin J. Pfeiffer, Sebastian T. Balbach, Telma C. Esteves, Nicola Crosetto and Michele Boiani

Int. J. Dev. Biol. (doi: 10.1387/ijdb.103197mp)

Active loss of DNA methylation in two-cell stage goat embryos

Jung S. Park, Doosoo Lee, Sunwha Cho, Sang-Tae Shin and Yong-Kook Kang

Int. J. Dev. Biol. (2010) 54: 1323-1328

Challenges and strategies for generating therapeutic patient-specific hemangioblasts and hematopoietic stem cells from human pluripotent stem cells

Ann Peters, Paul W. Burridge, Marina V. Pryzhkova, Michal A. Levine,Tea-Soon Park, Christopher Roxbury, Xuan Yuan, Bruno Péault and Elias T. Zambidis Int. J. Dev. Biol. (2010) 54: 965-990

Novel roles for Notch, Wnt and Hedgehog in hematopoesis derived from human pluripotent stem cells

Chantal Cerdan and Mickie Bhatia

Int. J. Dev. Biol. (2010) 54: 955-964

Estrogenic in vitro assay on mouse embryonic Leydig cells

Gina La Sala, Donatella Farini and Massimo De Felici

Int. J. Dev. Biol. (2010) 54: 717-722

Placental metabolic reprogramming: do changes in the mix of energy-generating substrates modulate fetal growth?

Nicholas P. Illsley, Isabella Caniggia and Stacy Zamudio

Int. J. Dev. Biol. (2010) 54: 409-419

Reprogramming of melanoma cells by embryonic microenvironments

Alejandro Díez-Torre, Ricardo Andrade, Cristina Eguizábal, Elixabete López, Jon Arluzea, Margarita Silió and Juan Aréchaga

Int. J. Dev. Biol. (2009) 53: 1563-1568

Genome reprogramming during sporulation

Jerome Govin and Shelley L. Berger

Int. J. Dev. Biol. (2009) 53: 425-432

Foetal germ cells: striking the balance between pluripotency and differentiation

Patrick Western

Int. J. Dev. Biol. (2009) 53: 393-409

5 yr ISI Impact Factor (2009) = 3.253

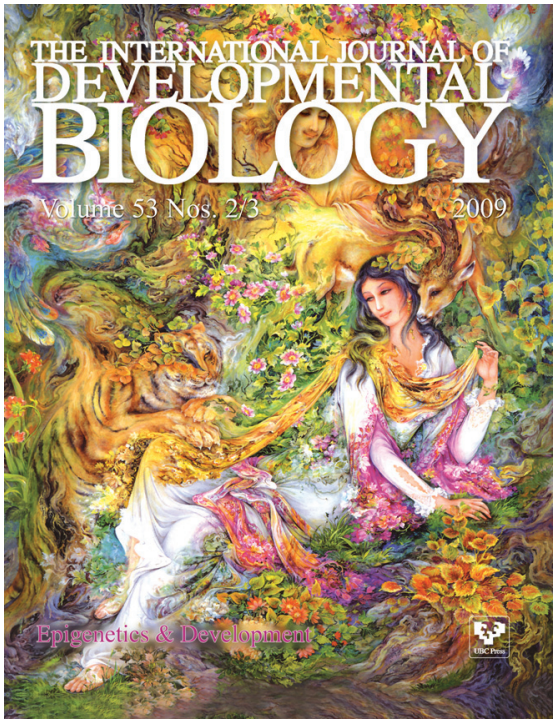

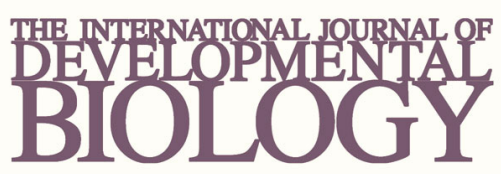

Volume 54 Nos. $6 / 7$
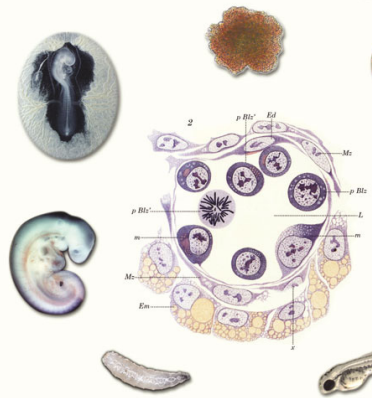

Developmental Hematopoiesis
Special Issue
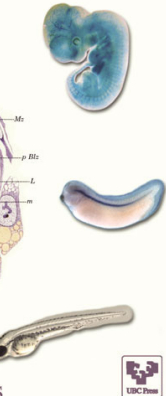

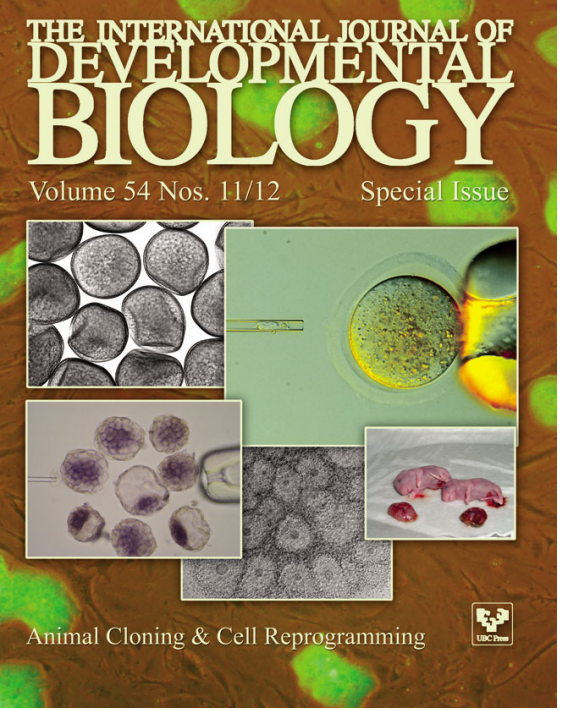

